Published in final edited form as:

J Dent Res. 2008 April ; 87(4): 328-333.

\title{
Periodontal Pathogens and Gestational Diabetes Mellitus
}

\author{
A.P. Dasanayake ${ }^{1,{ }^{*}, \text { N. Chhun }}{ }^{1}$, A.C.R. Tanner ${ }^{4}$, R.G. Craig ${ }^{2}$, M.J. Lee $^{3}$, A.F. Moore ${ }^{1}$, and \\ R.G. Norman ${ }^{1}$ \\ 1Department of Epidemiology and Health Promotion, New York University College of Dentistry, 345 East \\ 24th Street, New York, NY 10010, USA
}

2Department of Basic Sciences and Craniofacial Biology and Department of Periodontology and Implant Dentistry, New York University College of Dentistry, 345 East 24th Street, New York, NY 10010, USA

3Department of Obstetrics, Gynecology \& Reproductive Sciences, Yale University School of Medicine, New Haven, CT, USA

4Department of Molecular Genetics, The Forsyth Institute, Boston, MA, USA

\begin{abstract}
In previous cross-sectional or case-control studies, clinical periodontal disease has been associated with gestational diabetes mellitus. To test the hypothesis that, in comparison with women who do not develop gestational diabetes mellitus, those who do develop it will have had a greater exposure to clinical and other periodontal parameters, we measured clinical, bacteriological (in plaque and cervico-vaginal samples), immunological, and inflammatory mediator parameters 7 weeks before the diagnosis of gestational diabetes mellitus in 265 predominantly Hispanic (83\%) women in New York. Twenty-two cases of gestational diabetes mellitus emerged from the cohort (8.3\%). When the cases were compared with healthy control individuals, higher pre-pregnancy body mass index $(\mathrm{p}=$ 0.004), vaginal levels of Tannerella forsythia $(\mathrm{p}=0.01)$, serum C-reactive protein $(\mathrm{p}=0.01)$, and prior gestational diabetes mellitus $(\mathrm{p}=0.006)$ emerged as risk factors, even though the clinical periodontal disease failed to reach statistical significance (50\% in those with gestational diabetes mellitus $v s .37 .3 \%$ in the healthy group; $\mathrm{p}=0.38$ ).
\end{abstract}

\section{Keywords}

Maternal periodontal disease; gestational diabetes mellitus; Tannerella forsythia

\section{INTRODUCTION}

Gestational diabetes mellitus is defined as either onset or first recognition of glucose intolerance during pregnancy (ADA, 2004). Gestational diabetes mellitus is seen in 7\% of all pregnancies (over 200,000 cases annually) in the United States (ADA, 2004). Native Americans (5.8-14.3\%) (Benjamin et al., 1993; Murphy et al., 1993), Asian/Pacific Islanders (3.9-7.4\%) (Berkowitz et al., 1992; Keshavarz et al., 2005; Rosenberg et al., 2005; Thorpe et al., 2005; Silva et al., 2006), and Hispanics (3.5-7.5\%) (Forsbach et al., 1988; Berkowitz et al., 1992; Kieffer et al., 1999, 2001; Rosenberg et al., 2005) experience higher prevalence compared with African-Americans (1.7-3.9\%) (Dooley et al., 1991; Berkowitz et al., 1992; Kieffer et al., 2001; Rosenberg et al., 2005; Thorpe et al., 2005) and non-Hispanic Whites (2.2-2.6\%) (Berkowitz et al., 1992; Rosenberg et al., 2005; Thorpe et al., 2005).

*corresponding author, ad75@nyu.edu. 
Risk factors for gestational diabetes mellitus include older maternal age, a higher body mass index (ADA, 2004; Xiong et al., 2001; Keshavarz et al., 2005; Dudhbhai et al., 2006), prior gestational diabetes mellitus (ADA, 2004; Dudhbhai et al., 2006), family history of diabetes among first-degree relatives (ADA, 2004; Keshavarz et al., 2005; Dudhbhai et al., 2006), and being a member of a racial/ethnic group with a high prevalence of diabetes/gestational diabetes mellitus (ADA, 2004). In addition, increased levels of C-reactive protein (Wolf et al., 2003; Leipold et al., 2005), tumor necrosis factor- $\alpha$ (TNF- $\alpha$ ) (Kirwan et al., 2002; Winkler et al., 2002; Atègbo et al., 2006), and interleukin-6 (IL-6) (Atègbo et al., 2006) among women with gestational diabetes mellitus suggest a role of infection and inflammation in its etiology (Wolf et al., 2004). The purpose of this study was to examine the relationship between clinical and other periodontal disease parameters (bacteriological, immunological, and inflammatory aspects) and gestational diabetes mellitus.

\section{MATERIALS \& METHODS}

The study was approved by the appropriate Institutional Review Boards (New York University School of Medicine, Bellevue Hospital, and GCRC), and written informed consent was obtained from each woman. Inclusion criteria were: (1) gestational age of 15 to 23 wks; (2) singleton gestation; (3) ability to understand and sign the consent form; and (4) having a wellconfirmed estimated date of delivery from either the last menstrual period or ultrasound screening. Those who needed antibiotics before dental procedures and those who had taken antibiotics within 2 wks prior to sample collection were excluded.

Initial screening for gestational diabetes mellitus was performed with a one-hour 50-g oral Glucose Challenge Test at an initial pre-natal care visit, and if gestational diabetes mellitus had not yet been diagnosed, at 24 to 28 wks of gestation. If the Glucose Challenge Test value was greater than $140 \mathrm{mg} / \mathrm{dL}$, a three-hour 100-g oral Glucose Tolerance Test was given. If 2 of the 4 values in the Glucose Tolerance Test were at or above the cut-off levels (fasting glucose $\geq 95 \mathrm{mg} / \mathrm{dL}$, one-hour glucose $\geq 180 \mathrm{mg} / \mathrm{dL}$, two-hour glucose $\geq 155 \mathrm{mg} / \mathrm{dL}$, or three-hour glucose $\geq 140 \mathrm{mg} / \mathrm{dL}$ ), then gestational diabetes mellitus was diagnosed (Carpenter and Coustan, 1982).

Data on brushing, flossing, dental visits, and alcohol, cigarette, and drug use were collected by means of a pre-tested self-administered questionnaire (English or Spanish). Pre-pregnancy body mass index was determined at the time of enrollment. Clinical periodontal data, plaque, blood, and cervico-vaginal samples were collected from each woman. Mean gestational age for oral examination and plaque sample collection was $18.2 \mathrm{wks}(\mathrm{SD}=3.4)$, and for blood and cervico-vaginal sample collection, 17.9 wks $(\mathrm{SD}=3.3)$.

Subgingival pooled plaque samples were collected from the mesial and buccal sites of first molars by means of a sterile metal scalar. When the first molar was not available, either the second molar, third molar, second premolar, or the first premolar (in the order of availability) was used. Samples were placed in $0.1 \mathrm{~mL}$ TE buffer (50 mM Tris, $1 \mathrm{mM}$ EDTA, pH 7.6) and stored at $-80^{\circ} \mathrm{C}$ within $4 \mathrm{hrs}$ of collection. Oral examinations were conducted by calibrated dentists using the Periodontal Screening and Recording method and Periowise ${ }^{\circledR}$ probes (Premier Dental Products, Plymouth Meeting, PA, USA). Probing pocket depth in mesial, central, and distal sites of buccal and lingual surfaces and bleeding on probing were recorded on each sampled tooth. Clinical periodontal disease was defined as the presence of at least 1 pocket $>3 \mathrm{~mm}$ (beyond the green mark on the probe). Those with signs of periodontal disease were advised to visit their regular dentists and/or were given a referral letter.

Cervico-vaginal samples were collected by a sterile speculum examination. Two polyestertipped sterile swabs (Fisher Scientific, Hampton, NH, USA) were introduced into the posterior 
fornix of the vagina and left in place for $30 \mathrm{sec}$, then were rotated a minimum of 6 times. By the same technique, third and fourth swabs were then placed intra-cervically to obtain cervical secretions. Every attempt was made to ensure that cervical samples were not contaminated by the vaginal flora. All samples were placed in $0.1 \mathrm{~mL}$ TE buffer $(50 \mathrm{mM}$ Tris, $1 \mathrm{mM}$ EDTA, $\mathrm{pH}$ 7.6) and stored in a $-80^{\circ} \mathrm{C}$ freezer. Cervical samples were not collected at visits during which the woman bled (less than $0.5 \%$ ).

Blood samples (approximately $6 \mathrm{~mL}$ ) were drawn by a certified phlebotomist, left at room temperature $\left(20-25^{\circ} \mathrm{C}\right)$ for $30 \mathrm{~min}$, and then transferred to a refrigerator $\left(2-8^{\circ} \mathrm{C}\right)$ until centrifuged (Drucker Model 614B, Philipsburg, PA, USA) within $2 \mathrm{hrs}$ at $3150 \mathrm{rpm}$ for 20 $\mathrm{min}$. Each specimen was divided into a minimum of $40.5-\mathrm{mL}$ aliquots of serum and stored in a $-80^{\circ} \mathrm{C}$ freezer until transportation to labs on dry ice by express mail.

Plaque and cervico-vaginal samples were assayed at The Forsyth Institute (Boston, MA, USA) with DNA probes (Socransky et al., 2004). For vaginal and cervical samples, DNA was extracted before DNA probe assay with the use of a DNeasy® Tissue Kit (QIAGEN Sciences, Germantown, MD, USA) according to the manufacturer's protocol.

Serum samples were analyzed for IgG antibodies against cell-surface antigens of Porphyromonas gingivalis and Tannerella forsythia by a modified (Craig et al., 2002) enzymelinked immunosorbent assay at the New York University College of Dentistry laboratories (Ebersole et al., 1985). C-reactive protein, IL-6, and TNF- $\alpha$ levels were measured at Yale University (New Haven, CT, USA) with the commercially available Immulite ${ }^{\circledR}$ chemiluminescent enzyme immunometric assay (Diagnostic Products Corp., Los Angeles, CA, USA). Gestational diabetes mellitus status was masked to all laboratories.

In a nested case-control fashion, gestational diabetes mellitus cases were compared with healthy control individuals by parametric and non-parametric methods (SAS Version 9.1, SAS Institute, Cary, NC, USA). Bacteriological levels were transformed to $\log _{10}$ values (after the addition of 0.5 to raw values to replace zeros). Odds Ratios and $95 \%$ Confidence Intervals were calculated. Bacteriological and cytokine levels were treated as continuous variables. Following bivariate estimation of risk, multivariable logistic regression analysis was performed with adjustment for prior gestational diabetes mellitus (factor with the highest odds ratio) and the use of one other variable in the model to assess the independent effect of the latter. Inclusion of more than 2 independent variables in each model resulted in unstable models. Two-sided type I error probability $\leq 0.05$ was considered as the level of significance.

\section{RESULTS}

Seventy-six percent of the participants had only a high school education, and $43 \%$ were married. Thirty-percent had a self-reported annual family income under $\$ 5,000,52 \%, \$ 5,000$ $\$ 24,999,14 \%, \$ 25,000-\$ 49,000$, and only $4 \%$ had an income over $\$ 50,000$.

The prevalence of gestational diabetes mellitus was $8.3 \%$ (total of 22; 15 with GDMA1, and seven with GDMA2). Three additional women were diagnosed as GDMA2 vs. type B, indicating that they probably were diabetic prior to pregnancy and were excluded from the analyses. Mean gestational age at gestational diabetes mellitus diagnosis was $24.9 \mathrm{wks}$ (SD = 7.8).

Group comparisons are shown in Tables 1-4. Women with gestational diabetes mellitus were older $(p=0.07)$, had a significantly higher pre-pregnancy body mass index $(p=0.004)$, and a history of prior gestational diabetes mellitus $(p=0.006)$. More women with gestational diabetes mellitus were current/previous smokers $(\mathrm{p}=0.09)$. Their oral hygiene practices and dentalcare-seeking patterns were similar (Table 1). Women with gestational diabetes mellitus 
delivered at an earlier gestational age $(p=0.004)$, and had a higher incidence of premature rupture of membranes $(\mathrm{p}=0.04)$, and chorioamnionitis $(\mathrm{p}=0.04$; Table 2$)$.

Women with gestational diabetes mellitus also had higher vaginal levels of T. forsythia $(\mathrm{p}=$ 0.01 ), but their clinical periodontal disease, though higher (50\%), was not significantly different from that in the non-gestational diabetes mellitus control individuals $(37.3 \% ; \mathrm{p}=$ $0.38)$. $P$. gingivalis $(\mathrm{p}=0.39)$ and $T$. forsythia $(\mathrm{p}=0.73)$ specific serum $\operatorname{IgG}$ samples were not statistically significantly different between the two groups. Although the women with gestational diabetes mellitus had higher levels of C-reactive protein, TNF- $\alpha$, and IL-6, only Creactive protein levels reached statistical significance $(\mathrm{p}=0.01$; Table 3$)$.

Higher vaginal levels of $T$. forsythia $(\mathrm{OR}=1.27 ; 95 \% \mathrm{CI}=1.05-1.55)$, higher C-reactive protein levels $(\mathrm{OR}=2.01 ; 95 \% \mathrm{CI}=1.02-3.96)$, prior gestational diabetes mellitus $(\mathrm{OR}=8.48 ; 95 \%$ $\mathrm{CI}=2.19-32.82)$, and higher pre-pregnancy body mass index $(\mathrm{OR}=1.17 ; 95 \% \mathrm{CI}=1.08-1.27)$ were all significantly associated with gestational diabetes mellitus. In the multivariable analysis that adjusted for prior gestational diabetes mellitus, higher pre-pregnancy body mass index $(\mathrm{OR}=1.16 ; 95 \% \mathrm{CI}=1.07-1.26)$ and vaginal levels of $T$. forsythia $(\mathrm{OR}=1.31 ; 95 \% \mathrm{CI}=$ 1.06-1.60) still remained significant.

Although not predictors of gestational diabetes mellitus, premature rupture of membranes (OR $=4.64 ; 95 \% \mathrm{CI}=1.46-14.77)$ and chorioamnionitis $(\mathrm{OR}=3.76 ; 95 \% \mathrm{CI}=1.18-12.05)$ during the current pregnancy were significantly associated with gestational diabetes mellitus.

\section{DISCUSSION}

Clinical periodontal disease has been previously associated with gestational diabetes mellitus in cross-sectional (Novak et al., 2006; Xiong et al., 2006) or case-control studies (Millar and Offenbacher, personal communication). In our study, we measured clinical and other periodontal-disease-related parameters at least $7 \mathrm{wks}$ prior to the diagnosis of gestational diabetes mellitus.

The prevalence of gestational diabetes mellitus (8.3\%) was higher compared with the 4.1\%-5.4\% previously reported for Hispanics (Berkowitz et al., 1992; Kieffer et al., 1999, 2001), perhaps due to the higher Glucose Tolerance Test cut-off levels previously used (fasting glucose $\geq 105 \mathrm{mg} / \mathrm{dL}$, one-hour glucose $\geq 190 \mathrm{mg} / \mathrm{dL}$, two-hour glucose $\geq 165 \mathrm{mg} / \mathrm{dL}$, or threehour glucose $\geq 145 \mathrm{mg} / \mathrm{dL}$ ).

Pre-pregnancy body mass index and prior gestational diabetes mellitus are known risk factors for gestational diabetes mellitus (Xiong et al., 2001; ADA, 2004; Keshavarz et al., 2005; Dudhbhai et al., 2006). Additionally, gestational diabetes mellitus has been linked to preeclampsia (Xiong et al., 2001; Khatun et al., 2005), cesarean delivery (Xiong et al., 2001; Keshavarz et al., 2005; Khatun et al., 2005; Johns et al., 2006), premature rupture of membranes (Xiong et al., 2001; Yang et al., 2002), and preterm delivery (Xiong et al., 2001; Yang et al., 2002; Hedderson et al., 2003). However, other than delivering at an earlier gestational age and having a higher incidence of premature rupture of membranes and chorioamnionitis, no other pregnancy outcomes were significantly associated with gestational diabetes mellitus in our study, perhaps due to the smaller study size.

Elevated C-reactive protein levels, IL-6, and TNF- $\alpha$ in women with gestational diabetes mellitus have been shown to suggest a role of inflammation in the etiology of gestational diabetes mellitus. It is known that IL- 6 and TNF- $\alpha$ interfere with insulin signaling, and are also insulin antagonists. Therefore, sustained elevated levels of IL- 6 and TNF- $\alpha$ can interfere with carbohydrate metabolism, and consequently cause glucose intolerance that can result in gestational diabetes mellitus. In our study, women with gestational diabetes mellitus had higher 
C-reactive protein, TNF- $\alpha$, and IL-6 levels, though only the C-reactive protein levels reached statistical significance. Similarly, clinical measures of periodontal disease in the gestational diabetes mellitus group were higher (though not significant, due to study limitations). As such, it can be argued that periodontal-disease-induced inflammatory mediators may further aggravate insulin resistance, perhaps exacerbate the pre-existing pregnancy-induced insulin resistance, and further impair glucose tolerance.

Higher vaginal levels of $T$. forsythia were significantly associated with gestational diabetes mellitus, even with our small sample $(\mathrm{p}=0.01)$. However, the plaque levels of $T$. forsythia, a more plausible periodontal disease parameter, were not significantly associated with gestational diabetes mellitus. The most likely explanation for this is the study's inadequate power to show differences in plaque levels of $T$. forsythia between women with gestational diabetes mellitus and those without it. The same is true for cervical levels. This may be due to the higher prevalence of $T$. forsythia in plaque (60\%) and cervical samples (30\%), compared with the lower prevalence of $T$. forsythia in vaginal samples (13\%) among control women. Others have observed an increased incidence of chorioamnionitis and premature rupture of membranes, which are clinical conditions associated with increased inflammatory cytokines and oxidative stress that can occur with gestational diabetes mellitus and increased oral $T$. forsythia colonization (Sawamoto et al., 2005; Biri et al., 2006). A literature review reported on the presence of $T$. forsythia in other extra-oral host tissues, such as atheromatous plaque, coronary stenotic artery plaque, atherosclerotic vessels, occluded arteries in persons with Buerger disease, and bronchial tissues in embalmed cadavers (Tanner and Izard, 2006), lending support to the possibility of the presence of these organisms in extra-oral sites.

The smaller number of women with gestational diabetes mellitus (22) was a limitation of our study. Original data came from a prospective study designed to evaluate the association between maternal periodontal parameters and preterm birth and was not powered to evaluate the association between periodontal disease and gestational diabetes mellitus. However, under the fixed values of the available 22 cases and 240 control individuals (three were excluded due to possible prior diabetes), one-sided $\alpha=0.05$, and $13 \%$ exposure frequency (vaginal $T$. forsythia prevalence) among control individuals, the study had $80 \%$ power, but only to detect a four-fold increase in the risk of gestational diabetes mellitus. In contrast, a two-sample $t$ test with a 0.05 two-sided significance level will have $80 \%$ power to detect an effect size of 0.64 when the sample sizes in the two groups are 22 and 240, respectively. An effect size of 0.64 is considered a moderate-to-large effect in general (Cohen, 1992).

The use of periodontal screening and recording may explain why clinical periodontal disease was not significant. Pre-pregnancy body mass index, although significant, was based on individual recall. This might have diluted the true association due to random misclassification of body mass index. It is also possible that we failed to detect other true risk factors (i.e., age) due to small study size. Similarly, our inability to show significant differences in $T$. forsythia in plaque and cervical samples may not threaten the internal consistency of our findings. Last, although gestational diabetes mellitus diagnosis was made $7 \mathrm{wks}$ after the collection of plaque, blood, and cervico-vaginal samples, the date of gestational diabetes mellitus diagnosis does not necessarily mean the date of gestational diabetes mellitus onset. Future studies should measure periodontal parameters prior to the true onset of gestational diabetes mellitus.

Strengths of our study include the data on multiple parameters related to periodontal disease collected prior to gestational diabetes mellitus diagnosis and independent evaluation of biological samples at different laboratories that were masked to gestational diabetes mellitus status. 
We conclude that the presence of $T$. forsythia in vaginal flora is a potential risk factor for gestational diabetes mellitus, but this should be confirmed in future studies before consideration of its clinical significance, due to the study limitations discussed above.

\section{Acknowledgements}

Rosemary Wein, M. Christy Jared, May Tam, and Ramona Garcia (NYU School of Medicine) provided clinical assistance; S.C. Lu and Jay Theva (The Forsyth Institute), S. Joseph Huang (Yale), and Alice Chu and Dr. Robert Boylan (NYU College of Dentistry) assisted with laboratory assays. The study was supported by Research Grant 5 RO1 DE15594 from the National Institute of Dental and Craniofacial Research, National Institutes of Health, Bethesda, MD 20892, USA.

\section{References}

ADA. Gestational diabetes mellitus. Diabetes Care 2004;27(Suppl 1):88-90.

Atègbo JM, Grissa O, Yessoufou A, Hichami A, Dramane KL, Moutairou K, et al. Modulation of adipokines and cytokines in gestational diabetes and macrosomia. J Clin Endocrinol Metab 2006;91:4137-4143. [PubMed: 16849405]

Benjamin E, Winters D, Mayfield J, Gohdes D. Diabetes in pregnancy in Zuni Indian women. Prevalence and subsequent development of clinical diabetes after gestational diabetes. Diabetes Care 1993;16:1231-1235. [PubMed: 8404425]

Berkowitz GS, Lapinski RH, Wein R, Lee D. Race/ethnicity and other risk factors for gestational diabetes. Am J Epidemiol 1992;135:965-973. [PubMed: 1595695]

Biri A, Onan A, Devrim E, Babacan F, Kavutcu M, Durak I. Oxidant status in maternal and cord plasma and placental tissue in gestational diabetes. Placenta 2006;27:327-332. [PubMed: 16338477]

Carpenter MW, Coustan DR. Criteria for screening tests for gestational diabetes. Am J Obstet Gynecol 1982;144:768-773. [PubMed: 7148898]

Cohen J. A power primer: quantitative methods in psychology. Psycholog Bull 1992;112:155-159.

Craig RG, Boylan R, Yip J, Mijares D, Imam M, Socransky SS, et al. Serum IgG antibody response to periodontal pathogens in minority populations: relationship to periodontal disease status and progression. J Periodontal Res 2002;37:132-146. [PubMed: 12009183]

Dooley SL, Metzger BE, Cho NH. Gestational diabetes mellitus. Influence of race on disease prevalence and perinatal outcome in a U.S. population. Diabetes 1991;40(Suppl 2):25-29. [PubMed: 1748260]

Dudhbhai M, Lim L, Bombard A, Juliard K, Meenakshi B, Trachelenberg Y, et al. Characteristics of patients with abnormal glucose challenge test and normal oral glucose tolerance test results: comparison with normal and gestational diabetic patients. Am J Obstet Gynecol 2006;194:42-45.

Ebersole JL, Taubman MA, Smith DJ. Local antibody responses in periodontal diseases. J Periodontol 1985;56(11 Suppl):51S-55S.

Forsbach G, Contreras-Soto JJ, Fong G, Flores G, Moreno O. Prevalence of gestational diabetes and macrosomic newborns in a Mexican population. Diabetes Care 1988;11:235-238. [PubMed: 3416676]

Hedderson MM, Ferrara A, Sacks DA. Gestational diabetes mellitus and lesser degrees of pregnancy hyperglycemia: association with increased risk of spontaneous preterm birth. Obstet Gynecol 2003;102:850-856. [PubMed: 14551018]

Johns K, Olynik C, Mase R, Kreisman S, Tildesley H. Gestational diabetes mellitus outcome in 394 patients. J Obstet Gynaecol Can 2006;28:122-127. [PubMed: 16643713]

Keshavarz M, Cheung NW, Babaee GR, Moghadam HK, Ajami ME, Shariati M. Gestational diabetes in Iran: incidence, risk factors and pregnancy outcomes. Diabetes Res Clin Pract 2005;69:279-286. [PubMed: 16098925]

Khatun N, Latif SA, Uddin MM. Pregnancy associated complications of mothers with gestational diabetes mellitus. Mymensingh Med J 2005;14:196-198. [PubMed: 16056211]

Kieffer EC, Nolan GH, Carman WJ, Sanborn CZ, Guzman R, Ventura A. Glucose tolerance during pregnancy and birth weight in a Hispanic population. Obstet Gynecol 1999;94(5 Pt 1):741-746. [PubMed: 10546721] 
Kieffer EC, Carman WJ, Gillespie BW, Nolan GH, Worley SE, Guzman JR. Obesity and gestational diabetes among African-American women and Latinas in Detroit: implications for disparities in women's health. J Am Med Women's Assoc 2001;56:181-187. 196.

Kirwan JP, Hauguel-De Mouzon S, Lepercq J, Challier JC, Huston-Presley L, Friedman JE, et al. TNFalpha is a predictor of insulin resistance in human pregnancy. Diabetes 2002;51:2207-2213. [PubMed: 12086951]

Leipold H, Worda C, Gruber CJ, Prikoszovich T, Wagner O, Kautzky-Willer A. Gestational diabetes mellitus is associated with increased C-reactive protein concentrations in the third but not second trimester. Eur J Clin Invest 2005;35:752-757. [PubMed: 16313251]

Murphy NJ, Bulkow LR, Schraer CD, Lanier AP. Prevalence of diabetes mellitus in pregnancy among Yup'ik Eskimos, 1987-1988. Diabetes Care 1993;16:315-317. [PubMed: 8422799] erratum in Diabetes Care 16:667, 1993

Novak KF, Taylor GW, Dawson DR, Ferguson JE 2, Novak MJ. Periodontitis and gestational diabetes mellitus: exploring the link in NHANES III. J Public Health Dent 2006;66:163-168. [PubMed: 16913241]

Rosenberg TJ, Garbers S, Lipkind H, Chiasson MA. Maternal obesity and diabetes as risk factors for adverse pregnancy outcomes: differences among 4 racial/ethnic groups. Am J Public Health 2005;95:1545-1551. [PubMed: 16118366]

Sawamoto Y, Sugano N, Tanaka H, Ito K. Detection of periodontopathic bacteria and an oxidative stress marker in saliva from periodontitis patients. Oral Microbiol Immunol 2005;20:216-220. [PubMed: 15943765]

Silva JK, Kaholokula JK, Ratner R, Mau M. Ethnic differences in perinatal outcome of gestational diabetes mellitus. Diabetes Care 2006;29:2058-2063. [PubMed: 16936153]

Socransky SS, Haffajee AD, Smith C, Martin L, Haffajee JA, Uzel NG, et al. Use of checkerboard DNADNA hybridization to study complex microbial ecosystems. Oral Microbiol Immunol 2004;19:352362. [PubMed: 15491460]

Tanner AC, Izard J. Tannerella forsythia, a periodontal pathogen entering the genomic era. Periodontol 2000 2006;42:88-113. [PubMed: 16930308]

Thorpe LE, Berger D, Ellis JA, Bettegowda VR, Brown G, Matte T, et al. Trends and racial/ethnic disparities in gestational diabetes among pregnant women in New York City, 1990-2001. Am J Public Health 2005;95:1536-1539. [PubMed: 16051928]

Winkler G, Cseh K, Baranyi E, Melczer Z, Speer G, Hajós P, et al. Tumor necrosis factor system in insulin resistance in gestational diabetes. Diabetes Res Clin Pract 2002;56:93-99. [PubMed: 11891016]

Wolf M, Sandler L, Hsu K, Vossen-Smirnakis K, Ecker JL, Thadhani R. First-trimester C-reactive protein and subsequent gestational diabetes. Diabetes Care 2003;26:819-824. [PubMed: 12610043]

Wolf M, Sauk J, Shah A, Vossen Smirnakis K, Jimenez-Kimble R, Ecker JL, et al. Inflammation and glucose intolerance: a prospective study of gestational diabetes mellitus. Diabetes Care 2004;27:2127. [PubMed: 14693961]

Xiong X, Saunders LD, Wang FL, Demianczuk NN. Gestational diabetes mellitus: prevalence, risk factors, maternal and infant outcomes. Int J Gynaecol Obstet 2001;75:221-228. [PubMed: 11728481]

Xiong X, Buekens P, Vastardis S, Pridjian G. Periodontal disease and gestational diabetes mellitus. Am J Obstet Gynecol 2006;195:1086-1089. [PubMed: 16846573]

Yang X, Hsu-Hage B, Zhang H, Zhang C, Zhang Y, Zhang C. Women with impaired glucose tolerance during pregnancy have significantly poor pregnancy outcomes. Diabetes Care 2002;25:1619-1624. [PubMed: 12196437] 
Table 1

Demographic, Pre-pregnancy, Behavioral, and Dental Characteristics of Study Participants

\begin{tabular}{|c|c|c|c|}
\hline Characteristic & $\mathbf{G D M}^{\S}$ & Non-GDM & $\mathbf{p}$ \\
\hline \multicolumn{4}{|l|}{ Demographics } \\
\hline Age: Mean yrs (SD) & $28.7(5.3)$ & $26.6(5.8)$ & $0.07^{b}$ \\
\hline \multicolumn{4}{|l|}{ Ethnicity: N (\%) } \\
\hline Hispanic & $17(77)$ & $200(83)$ & \multirow[t]{2}{*}{$0.55^{a}$} \\
\hline Non-Hispanic & $5(23)$ & $40(17)$ & \\
\hline \multicolumn{4}{|l|}{ Race: N $(\%)$} \\
\hline White & $17(77)$ & $204(85)$ & \multirow{3}{*}{$0.19^{a}$} \\
\hline Black & $2(9)$ & $26(11)$ & \\
\hline Asian & $3(14)$ & $10(4)$ & \\
\hline \multicolumn{4}{|l|}{ Pregnancy-related } \\
\hline Pre-pregnancy Body Mass Index: Mean (SD) & $30.5(7.9)$ & $25.5(4.4)$ & $0.004^{b^{*}}$ \\
\hline Family history of diabetes: $(\%)$ & 13.6 & 8.6 & $0.59^{a}$ \\
\hline $\mathrm{GDM}^{\S}$ in a prior pregnancy: $(\%)$ & 18.2 & 2.6 & $0.006^{a^{*}}$ \\
\hline Pre-eclampsia in a prior pregnancy: $(\%)$ & 9.1 & 3.0 & $0.17^{a}$ \\
\hline $\mathrm{PTD}^{I I}$ in a prior pregnancy: $(\%)$ & 9.1 & 4.6 & $0.30^{a}$ \\
\hline C-section in a prior pregnancy: $(\%)$ & 18.2 & 13.6 & $0.52^{a}$ \\
\hline \multicolumn{4}{|l|}{ Behavioral } \\
\hline \multicolumn{4}{|l|}{ Smoking (\%) } \\
\hline Current & 4.8 & 0.5 & \multirow[t]{3}{*}{$0.09^{a}$} \\
\hline Previous & 28.6 & 19.9 & \\
\hline Never & 66.7 & 79.6 & \\
\hline \multicolumn{4}{|l|}{ Alcohol use (\%) } \\
\hline Current & 0.0 & 0.5 & \multirow[t]{3}{*}{$1.00^{a}$} \\
\hline Previous & 40.0 & 39.2 & \\
\hline Never & 60.0 & 60.4 & \\
\hline \multicolumn{4}{|l|}{ Drug use $(\%)$} \\
\hline Current & 0.0 & 0.0 & \multirow[t]{3}{*}{$1.00^{a}$} \\
\hline Previous & 4.8 & 5.9 & \\
\hline Never & 95.2 & 94.1 & \\
\hline \multicolumn{4}{|l|}{ Dental habits } \\
\hline Brushing (per day): Mean (SD) & $2.2(0.4)$ & $2.3(0.6)$ & $0.19^{b}$ \\
\hline Flossing (per week): Mean (SD) & $3.7(5.0)$ & $3.9(5.3)$ & $0.92^{b}$ \\
\hline Dental visits (per year): Mean (SD) & $1.1(0.9)$ & $1.3(2.6)$ & $0.75^{b}$ \\
\hline
\end{tabular}

${ }^{a}$ Fisher's Exact Test.

${ }^{b}$ Wilcoxon Rank Sum Test.

* Statistically significant.

$\S_{\mathrm{GDM}}=$ gestational diabetes mellitus.

$\pi_{\mathrm{PTD}}=$ Preterm delivery. 


\section{Table 2}

Pregnancy Outcomes of Study Participants

\begin{tabular}{|c|c|c|c|}
\hline Characteristic & $\mathbf{G D M}^{\S}$ & Non-GDM & $\mathbf{p}$ \\
\hline Gestational age (wks): Mean (SD) & $37.4(2.8)$ & $38.8(2.5)$ & $0.004^{b^{*}}$ \\
\hline Birthweight (g): Mean (SD) & $3039.0(676.9)$ & $3293.4(628.3)$ & $0.14^{b}$ \\
\hline \multicolumn{4}{|l|}{ Baby gender: $\mathrm{N}(\%)$} \\
\hline Male & $12(57)$ & $105(46)$ & $0.37^{a}$ \\
\hline Female & $9(43)$ & $122(54)$ & \\
\hline Apgar 1: Mean (SD) & $8.3(2.1)$ & $8.5(1.3)$ & $0.81^{b}$ \\
\hline Apgar 5: Mean (SD) & $8.5(2.1)$ & $8.8(1.3)$ & $0.34^{b}$ \\
\hline \multicolumn{4}{|l|}{ Mode of delivery $(\%)$} \\
\hline Vaginal & 68.2 & 74.6 & $0.61^{a}$ \\
\hline C-section & 31.8 & 25.4 & \\
\hline Premature rupture of membranes $(\%)$ & 25.0 & 8.6 & $0.04^{a^{*}}$ \\
\hline Chorioamnionitis $(\%)$ & 25.0 & 9.2 & $0.04^{a^{*}}$ \\
\hline Pre-eclampsia $(\%)$ & 10.0 & 2.7 & $0.14^{a}$ \\
\hline
\end{tabular}

${ }^{a}$ Fisher's Exact Test.

${ }^{b}$ Wilcoxon Rank Sum Test.

Statistically significant.

$\S_{\mathrm{GDM}}=$ gestational diabetes mellitus. 
Table 3

Periodontal Disease Parameters of Study Participants

\begin{tabular}{|c|c|c|c|}
\hline Variable & GDM $^{\S}$ & Non-GDM & $\mathbf{p}$ \\
\hline Clinical periodontal disease (\%) & 50.0 & 37.3 & $0.38^{a}$ \\
\hline \multicolumn{4}{|l|}{ Maternal serum IgG levels against } \\
\hline$P$. gingivalis $(\% \text { high })^{c}$ & 90.9 & 82.3 & $0.39^{a}$ \\
\hline T. forsythia $(\% \text { high })^{c}$ & 86.4 & 88.7 & $0.73^{a}$ \\
\hline \multicolumn{4}{|c|}{ Bacteriological data $\left(\log _{10}\right)$ : Mean (SD) } \\
\hline \multicolumn{4}{|c|}{ Plaque } \\
\hline C. rectus & $2.5(2.9)$ & $3.5(2.6)$ & $0.22^{b}$ \\
\hline F. nucleatum ssp. nucleatum & $4.3(2.2)$ & $4.5(2.2)$ & $0.22^{b}$ \\
\hline T. forsythia & $2.9(3.0)$ & $3.2(2.9)$ & $0.64^{b}$ \\
\hline P. gingivalis & $1.6(2.8)$ & $2.5(2.8)$ & $0.32^{b}$ \\
\hline T. denticola & $2.3(2.7)$ & $2.8(2.7)$ & $0.33^{b}$ \\
\hline \multicolumn{4}{|l|}{ Vaginal } \\
\hline C. rectus & $1.9(2.5)$ & $1.2(2.2)$ & $0.14^{b}$ \\
\hline F. nucleatum ssp. nucleatum & $2.7(2.5)$ & $2.7(2.3)$ & $0.41^{b}$ \\
\hline T. forsythia & $1.3(2.4)$ & $0.3(1.6)$ & $0.01^{*}$ \\
\hline P. gingivalis & $0.6(2.0)$ & $0.4(1.7)$ & $0.48^{b}$ \\
\hline T. denticola & $0.6(1.9)$ & $0.8(2.0)$ & $0.71^{b}$ \\
\hline \multicolumn{4}{|l|}{ Cervical } \\
\hline C. rectus & $1.8(2.4)$ & $1.8(2.3)$ & $0.91^{b}$ \\
\hline F. nucleatum ssp. nucleatum & $1.9(2.5)$ & $2.9(2.3)$ & $0.17^{b}$ \\
\hline T. forsythia & $1.2(2.3)$ & $1.0(2.1)$ & $0.57^{b}$ \\
\hline P. gingivalis & $1.6(2.4)$ & $1.1(2.1)$ & $0.18^{b}$ \\
\hline T. denticola & $0.7(2.0)$ & $0.8(2.0)$ & $0.96^{b}$ \\
\hline \multicolumn{4}{|l|}{ Inflammatory markers: Mean (SD) } \\
\hline C-reactive protein $(\mathrm{mg} / \mathrm{dL})$ & $0.6(0.6)$ & $0.3(0.4)$ & $0.01^{b^{*}}$ \\
\hline $\mathrm{TNF}-\alpha(\mathrm{pg} / \mathrm{mL})$ & $16.1(12.5)$ & $13.2(10.3)$ & $0.27^{b}$ \\
\hline IL-6 (pg/mL) & $4.6(3.4)$ & $4.3(4.5)$ & $0.42^{b}$ \\
\hline
\end{tabular}

$a_{\text {Fisher's Exact Test. }}$

${ }^{b}$ Wilcoxon Rank Sum Test.

${ }^{c}$ Mean is $\geq 2$ standard deviations.

*

Statistically significant.

$\S_{\mathrm{GDM}}=$ gestational diabetes mellitus. 
Table 4

Effects of Periodontal Disease and Other Parameters on Gestational Diabetes Mellitus_-Bivariate and Multivariable Logistic Regression Analysis

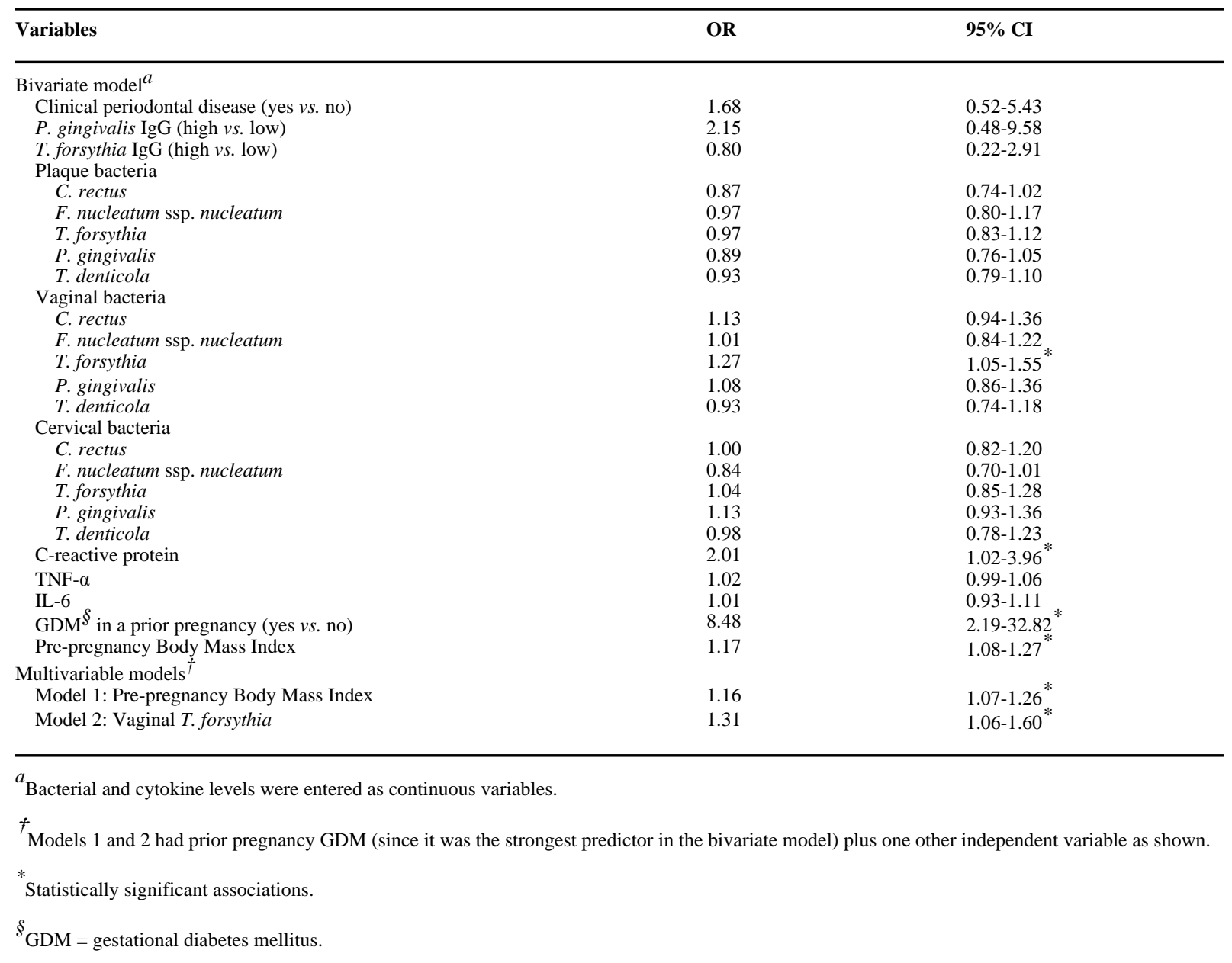

